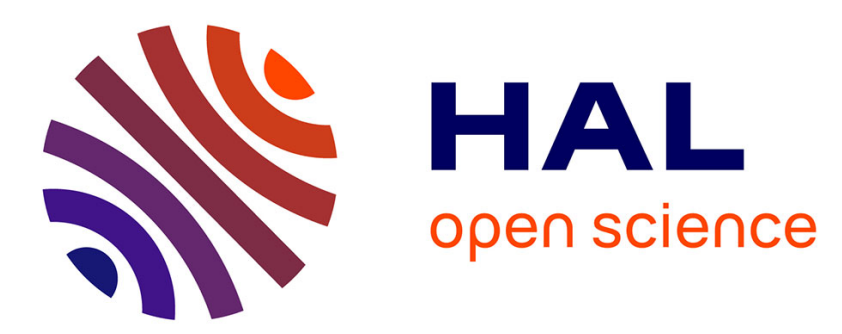

\title{
Influence of the crack-tip hydride concentration on the fracture toughness of Zircaloy-4
}

\author{
Graciela Bertolino, J. Perez Ipiña, G. Meyer
}

\section{To cite this version:}

Graciela Bertolino, J. Perez Ipiña, G. Meyer. Influence of the crack-tip hydride concentration on the fracture toughness of Zircaloy-4. Journal of Nuclear Materials, 2006, 348, pp.205-212. 10.1016/j.jnucmat.2005.09.017 . hal-00111508

\section{HAL Id: hal-00111508 \\ https://hal.science/hal-00111508}

Submitted on 26 Sep 2019

HAL is a multi-disciplinary open access archive for the deposit and dissemination of scientific research documents, whether they are published or not. The documents may come from teaching and research institutions in France or abroad, or from public or private research centers.
L'archive ouverte pluridisciplinaire HAL, est destinée au dépôt et à la diffusion de documents scientifiques de niveau recherche, publiés ou non, émanant des établissements d'enseignement et de recherche français ou étrangers, des laboratoires publics ou privés. 


\title{
Influence of the crack-tip hydride concentration on the fracture toughness of Zircaloy-4
}

\author{
G. Bertolino $^{\text {a,* }}$, J. Perez Ipiña ${ }^{\text {c,d }}$, G. Meyer ${ }^{\text {b,c }}$ \\ a LMS, CNRS UMR7649, Ecole Polytechnique, 91128 Palaiseau cedex, France \\ ${ }^{\mathrm{b}}$ Centro Atómico Bariloche, CNEA, 8400 Bariloche, Argentina \\ ${ }^{\mathrm{c}}$ CONICET, Argentina \\ d Universidad Nacional del Comahue, 8300 Neuquén, Argentina
}

The influence of a hydrogen concentration gradient at the crack-tip and hydride platelet orientation on the fracture toughness, fracture mode and micromechanisms of a Zircaloy-4 commercial alloy was studied. Fracture toughness was measured on CT specimens and the analysis was performed in terms of $J$-integral resistance curves at temperatures ranging from 293 to $473 \mathrm{~K}$. Fracture toughness results of specimens containing higher hydrides concentration near the crack-tip region, preferentially orientated in the crack plane, were compared to those obtained from specimens with a homogeneous hydrogen distribution and different platelet orientation; specimens were obtained by charging them in loaded and unloaded condition, respectively. Changes on both macroscopic and microscopic fracture behaviour were observed at temperatures ranging from 293 to $343 \mathrm{~K}$, and the results show the relevance of both hydride concentration and platelet orientation. The existence of a ductile-to-brittle transition is discussed at the light of these new results.

\section{Introduction}

The combination of radiation, oxidation and hydriding degrades the mechanical behaviour of fuel cladding during nuclear reactor operation. Zirconium alloys are the sole material employed for cladding tubes of nuclear fuel because of their neutron transparency. As zirconium is a hydride

\footnotetext{
* Corresponding author. Tel.: +33 169333305; fax: +33 169333507.

E-mail addresses: bertolin@cab.cnea.gov.ar, bertolin@lms. polytechnique.fr (G. Bertolino).
}

forming metal, the hydrogen absorption leads to the formation of different hydrides, with the subsequent degradation of mechanical properties. Inservice, as the total amount of hydrogen in a cladding increases, hydrides precipitate preferentially close to the outer surface of the cladding, which is the coolest one.

The factors reported to affect hydride platelet orientation in zirconium alloy are crystallographic texture, prior strain and applied stress [1]. Hydride precipitation under stress shows preference for the orientation of hydrides, where platelets precipitate parallel to the planes of highest principal stresses 
[1-4], this phenomenon being called stress-reorientation.

The influence of an uniform distribution of hydrides on the mechanical behaviour of zirconium-based alloys has been extensively studied, usually through uniaxial tensile tests [5-8]. The mode I crack growth behaviour of Zircaloy-4 has been also examined in a previous work [9]. The occurrence of a ductile-to-brittle transition with temperature and/or $\mathrm{H}$ content was reported in zirconium alloys with homogeneous hydrogen distribution, also under uniaxial tensile loading. This transition seems to be strongly dependent of the material microstructure, thermal history, hydrogen content, morphology and orientation of hydride precipitates [10]. However, fracture toughness testing did not reveal such transition for hydrogen levels under $2000 \mathrm{ppm}$ at temperatures between room temperature and $470 \mathrm{~K}$ [9].

When the above-mentioned results are intended to be transferred to industrial service conditions, a question immediately arises: is the homogeneous hydrogen distribution representative of the actual distribution present in a material submitted to service conditions, especially in cases where cracks could be present? When a crack is present in the in-service component, a non-homogeneous hydride precipitates distribution can be expected, with a larger presence of $\mathrm{H}$ in the crack-tip region, leading to a different behaviour of the crack and, very important, to a possible non-conservative condition when results from tests with homogeneous $\mathrm{H}$ distribution are employed.

The influence of a non-homogeneous distribution of hydrides has been examined in two recent works, when hydrides are present in the form of a layer or rim in cladding tubes [11], and also in the case of blisters in sheets [12], showing a significant loss of ductility with increasing hydrogen content and hydride rim thickness, although in the case of blister the fracture process was controlled apparently by the crack growth resistance of the substrate.

The aim of this study was to examine the influence of a concentration gradient of hydride precipi- tates in the near crack-tip region on the fracture behaviour of unirradiated Zircaloy-4 alloy under mode I loading. The objective of this hydrogen distribution has been to obtain specimens with a hydride distribution representative of a loaded component containing a crack or a defect. The study was carried out, by testing CT specimens, on recrystallized Zircaloy-4 with a crystallographic texture similar to that of as-fabricated Zircaloy-4 cladding tubes. Some aspects related to the ductile-to-brittle transition in this material are discussed.

\section{Materials and methods}

\subsection{Material and specimens}

The material of this study was a Zircaloy-4 in plate shape, hot and cold rolled to a final thickness of $6 \mathrm{~mm}$ and recrystallized leading to an equiaxed grain structure, with an average grain size of $8 \mu \mathrm{m}$. A summary of the principal alloying elements is given in Table 1. As a result of the previous plastic deformation processing, the sheet exhibited a strong texture with its basal pole tilted around $\pm 30^{\circ}$ away from the normal direction toward the transverse direction [9].

Standard fatigue pre-cracked compact tension (CT) specimens with dimensions in accordance with ASTM E 1820-99 [13] were employed to the characterization $(W=25.4 \mathrm{~mm})$, Fig. 1. The specimens were machined with the same thickness of the plate $(6 \mathrm{~mm})$, implying that the rolling plane was normal to the crack front, and the notch parallel to the rolling direction, Fig. 1.

\subsection{Hydrogen charging method}

The hydriding process was performed on specimens (pre) mechanically loaded in mode I. The mechanical loading process consisted of loading the specimen in a test machine until a desired $K$ (stress intensity factor), then by using a simple wedge the imposed displacement remains after the load is removed. At this point some load relaxation

Table 1

Chemical composition of material used

\begin{tabular}{|c|c|c|c|c|c|c|c|c|}
\hline \multicolumn{5}{|c|}{ Alloying elements (wt\%) } & \multicolumn{4}{|c|}{ Main impurities (ppm) } \\
\hline $\mathrm{Fe}$ & $\mathrm{Cr}$ & $\mathrm{FeCr}$ & $\mathrm{S}$ & $\mathrm{O}$ & $\mathrm{Al}$ & $\mathrm{C}$ & $\mathrm{Hf}$ & $\mathrm{Si}$ \\
\hline 0.21 & 0.1 & 0.31 & 1.42 & 0.125 & 25 & 110 & 52 & 39 \\
\hline
\end{tabular}




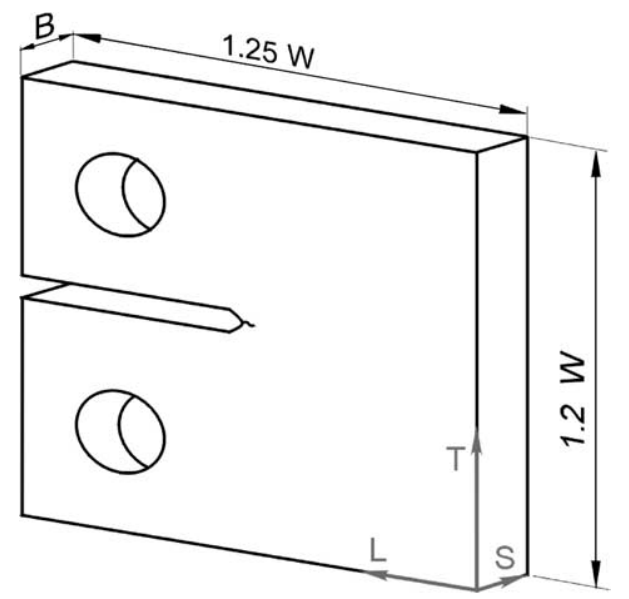

Fig. 1. Geometry and dimensions of employed CT specimens, $W=25.4 \mathrm{~mm}, B=6 \mathrm{~mm}$. The reference system corresponds to the specimen orientation related to the plate: $\mathrm{L}$ - long direction (rolling direction), $\mathrm{T}-$ transverse direction, and $\mathrm{S}$ - short direction.

occurs, so the effective $K$ is not well known. All the specimens were loaded at similar $K$ values, around $18 \mathrm{Mpa} \sqrt{ } \mathrm{m}$. In this way, a stress distribution characterized by high stress gradient, WestergaardIrwin type, was introduced in the specimen, making more hydrogen diffuse into the areas of highest stress levels, leading to a high hydrogen concentration gradient in the near crack-tip region. Two consecutive techniques were employed for the hydrogen charging; an electrochemical technique first, and then an annealing in a hydrogen rich atmosphere. Electrochemical charge was carried out at room temperature in a solution of $0.1 \mathrm{M} \mathrm{KOH}$ with a current density of $10 \mathrm{~mA} / \mathrm{cm}^{2}$ during a period of time determined by the desired final concentration. The annealing process was performed at $450{ }^{\circ} \mathrm{C}$ at hydrogen pressure between 1.5 and 3 bar. Then, the specimens were slowly cooled inside the furnace, and keeping the mechanical load. The specimens were unloaded after the cooling process was complete.

\subsection{Fracture tests}

ASTM E 1820-99 standard was followed, evaluating the $J-R$ curves by means of the single-specimen unloading compliance technique. The stable crack growth initiation value $\left(J_{\text {IC }}\right)$ was calculated when possible, while $J_{\mathrm{C}}$ was evaluated for the specimens exhibiting brittle fracture. $J_{\mathrm{C}}$ corresponds to the $J$ value at the fracture point. After the test, those specimens that exhibited only ductile behaviour were fatigue post-cracked to delineate the stable crack growth. Because the compliances were not measured on the load line, data corrections had to be made [14]. The tests were performed at temperatures between 293 and $473 \mathrm{~K}$. Specimens were heated by using two strip heaters and temperature measurement and control were performed by means of a K-type thermocouple placed close to the crack-tip. The temperature was controlled within $\pm 1 \mathrm{~K}$.

Some $J$ initiation values, mostly for tests at high temperature, were higher than the maximum valid $J$ $\left(133 \mathrm{~kJ} / \mathrm{m}^{2}\right)$ in accordance with standards for this material and with specimen thickness of $6 \mathrm{~mm}$. In these cases the $J$ initiation value is not $J_{\mathrm{IC}}$ but $J_{\mathrm{Q}}$ in accordance with the standard.

\subsection{Metallographic and fractographic analysis}

A standard procedure of mechanical polishing and chemical etching was carried out for the metallographies, with a solution of 45 pct glycerol, 45 pct $\mathrm{HNO}_{3}$ and 10 pct HF to reveal the microstructure and then a solution of 92 pet $\mathrm{HNO}_{3}$ and 8 pet $\mathrm{HF}$ to reveal the Zr-hydrides distribution.

After the tests, one-half of each specimen was observed through scanning electron microscopy (SEM) to study the fracture surface and hydride distribution; the remaining halves were prepared for hydrogen content measurements by inert gas fusion technique using a LECO ${ }^{\mathrm{TM}}$ hydrogen analyser. The accuracy of the hydrogen content measurement is $\pm 10 \mathrm{ppm}$. The $\mathrm{H}$ content was measured at least at five different locations, four of them along the remaining ligament as indicated in Fig. 2.

\section{Results and discussion}

The employed hydrogen charge produced hydride precipitates of $\delta$ phase type, platelet shaped, with a concentration along the crack path exponentially diminishing from its highest value at the crack-tip - Fig. 2 shows this behaviour for three specimens. This was the expected result due to the variation of hydrogen solubility with stress. Fig. 3 shows two micrographs of a specimen with $1634 \mathrm{H} \mathrm{ppm}$ at the crack-tip and $173 \mathrm{H} \mathrm{ppm}$ in the bulk (face LT), the variation on the hydride concentration as a function of the distance to the crack-tip can be clearly observed. Hydrides generally precipitated at grain boundaries, following 

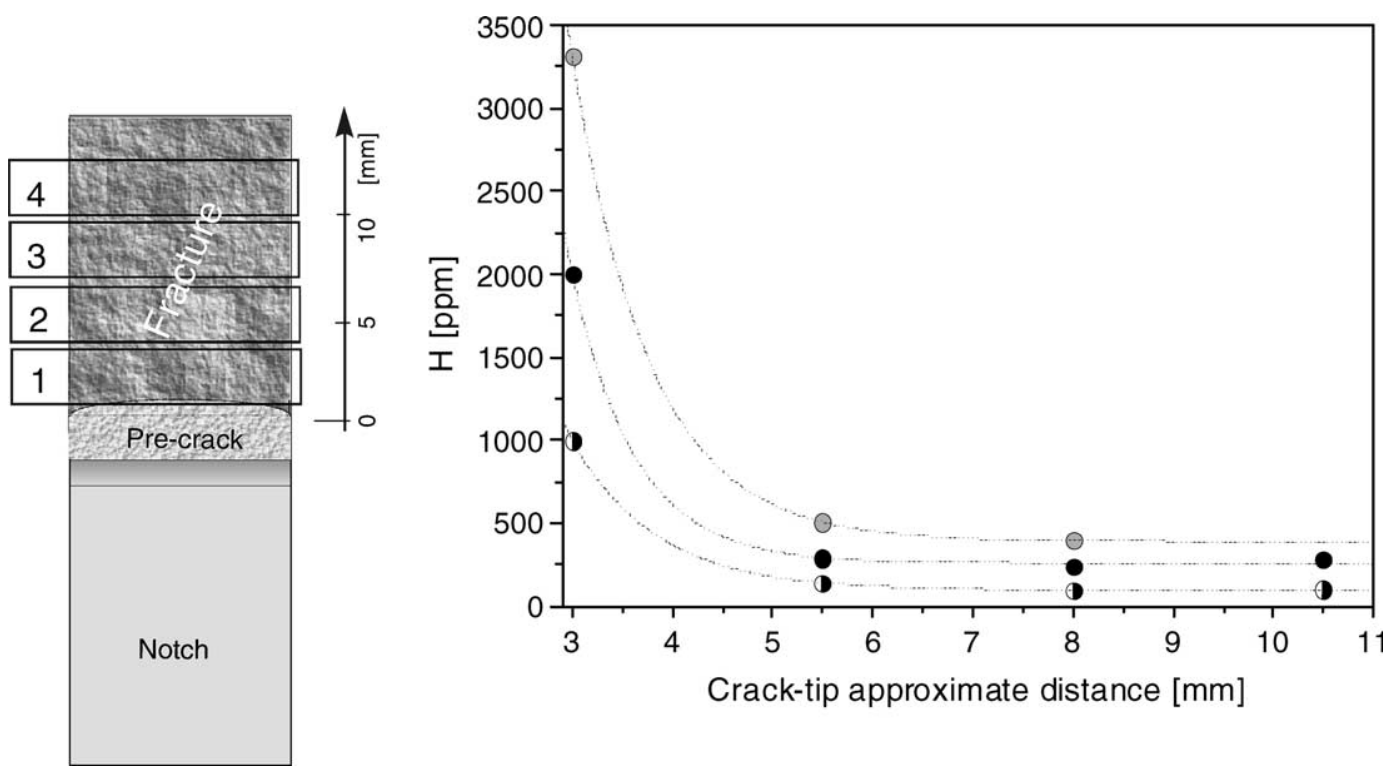

Fig. 2. Variation of $\mathrm{H}$ content along the remaining ligament.

their curvature; however, the formation of a continuous network of hydride along the grain boundaries was often observed for regions with medium hydrogen content, i.e. 173 ppm, Fig. 3(b). Transgranular precipitation was also found in the near crack-tip region, which corresponded to the highest concentration zone. Micrographs showed that the plane orientation in which platelets precipitated tended to be parallel (in average) to the LS plane and normal to the $\mathrm{T}$ direction, at least in the regions near the crack path, Fig. 3. Instead, in specimens charged without pre-stress, i.e. homogeneous distribution of hydrogen, the platelet orientation was parallel to the LT plane, Figs. 3(c) and 4. It had several times been reported that hydride precipitation under stress shows preferential orientation, where the normal to the platelet is parallel to the tensile stress direction [2]. This phenomenon is related to preferred nucleation and growth orientation and has been reported to occur in pressure tubes where the precipitation direction changes from circumferential to radial under certain specific stress state [1]. The platelets orientation in the present specimens was consistent with this process, Fig. 4. According to Hardie [15], the hydride orientation due to stress is extremely dependent of the temperature and the stress level, with a threshold stress $\left(\sigma_{\mathrm{th}}\right)$ depending on the annealing temperature and the material yield strength. Bell and Duncan [16], suggested, in a work on experimental determination of $\sigma_{\mathrm{th}}$, that $\sigma_{\text {th }}$ should reduce to a null value at a temperature of $704 \mathrm{~K}$. Regarding our experiments, all the tested specimens with homogeneous hydrogen distribution throughout the volume were heat treated at $723 \mathrm{~K}$ and no change in platelet orientation was observed; only those specimens with a mechanical load imposed during the hydrogen charge showed platelet preferentially orientated to the crack plane. These results are not in accordance with Bell's statement, but with Singh's who found no preferred orientation for tests carried out at $723 \mathrm{~K}$ with no load.

All specimens containing a non-homogeneous $\mathrm{H}$ distribution and tested at room temperature failed by brittle mode without previous stable crack growth in a range of $J_{\mathrm{C}}$ values from 15 to $25 \mathrm{~kJ} /$ $\mathrm{m}^{2}$ (corresponding to $K$ values from 38 to $50 \mathrm{MPa} \sqrt{ } \mathrm{m})$. Fig. 5 shows the corresponding $J_{\mathrm{C}}$ values plotted as a function of the $\mathrm{H}$ content far away from the crack-tip, i.e. in the region of the bulk hydrogen content; and, for comparison, the $J_{\text {IC }}$ values obtained by testing similar specimens with homogeneous hydrogen distribution in the specimen volume [9]. Comparing these results, it seems that, instead of the bulk $\mathrm{H}$ level, the hydride distribution and the platelet orientation near the crack-tip control the fracture behaviour, rendering it brittle due to a high local hydride concentration even when the bulk $\mathrm{H}$ level is low, or the high concentration zone is small. Results from SEM in situ test [17] at room temperature showed that when 

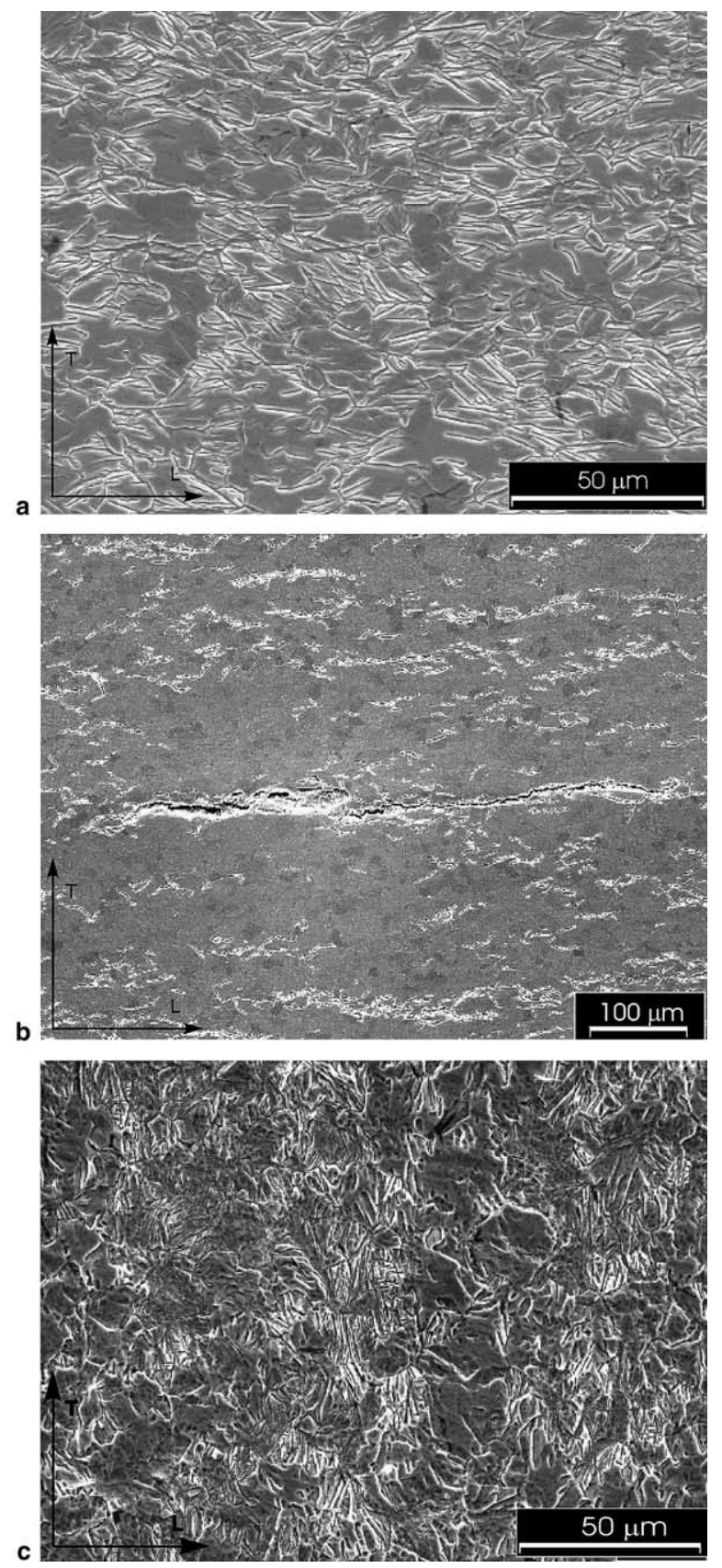

Fig. 3. Micrograph showing the hydride distribution in the same specimen (charged under stress), (a) near the crack-tip zone $(1634 \mathrm{H} \mathrm{ppm})$ and (b) far away from the crack-tip $(>8 \mathrm{~mm})$ and not far from the crack path $(173 \mathrm{H} \mathrm{ppm})$. Image (b) shows hydrides 'agglomeration' forming arrays on the L direction, LT plane. (c) Micrograph from a specimen charged without stress.

hydrides were oriented parallel to the crack propagation plane, the crack grows following a path of cracked hydrides either without or with minimum matrix plastic deformation.

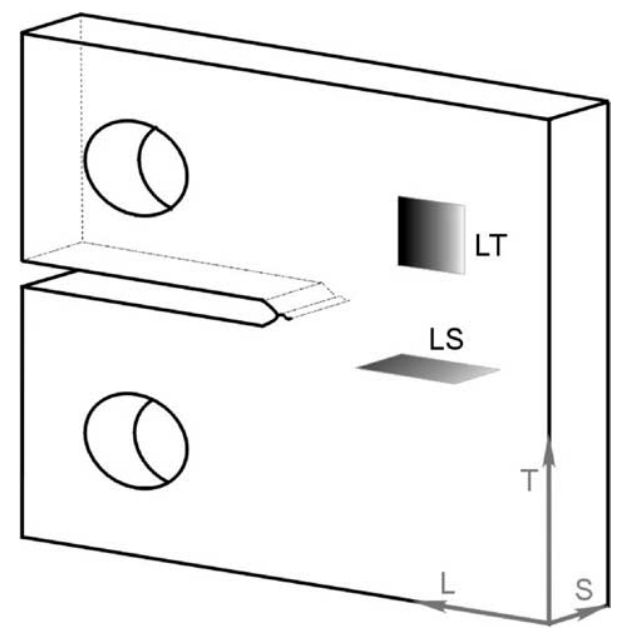

Fig. 4. Orientation of hydride platelets with (LS) and without (LT) mechanical loading.

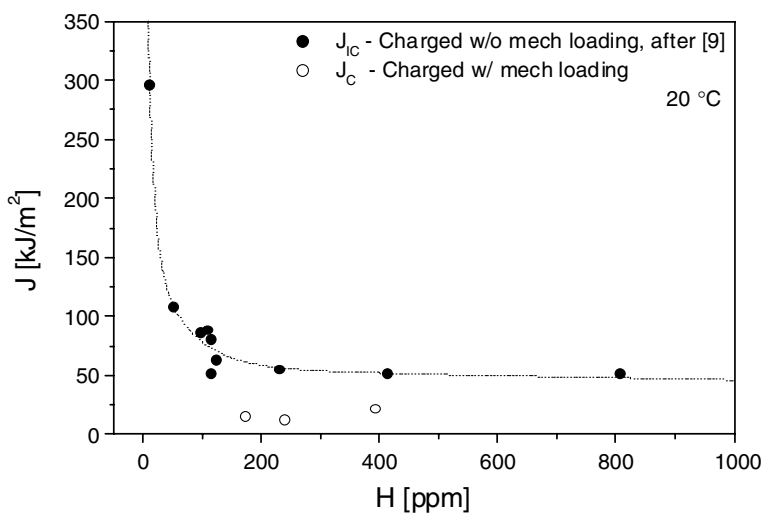

Fig. 5. $J$ values for specimens tested at room temperature (open circles) and $J$ values obtained from specimens charged without mechanical loading also tested at room temperature [9].

The observation of the fracture surfaces of specimens charged under stress showed that the dominant fracture micromechanism at room temperature was cleavage, Fig. 6; in contrast to the one observed for the homogeneous $\mathrm{H}$ distribution where all specimens fractured by nucleation and coalescence of microvoids. As can be observed in Fig. 7, some specimens showed a fracture 'transition' region between the fatigue pre-crack zone and that of fast crack propagation during the test, where microcracks normal to the crack growth direction are present. This area could be interpreted as produced by a sub-critical crack growth mechanism developed during the hydrogen charging stage. The applied pre-stress in these specimens 


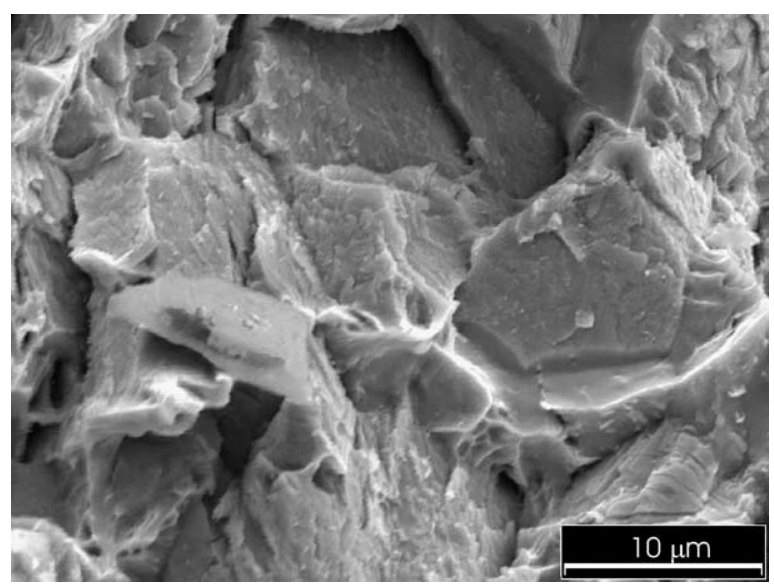

Fig. 6. Fracture surfaces of specimens tested at room temperature.

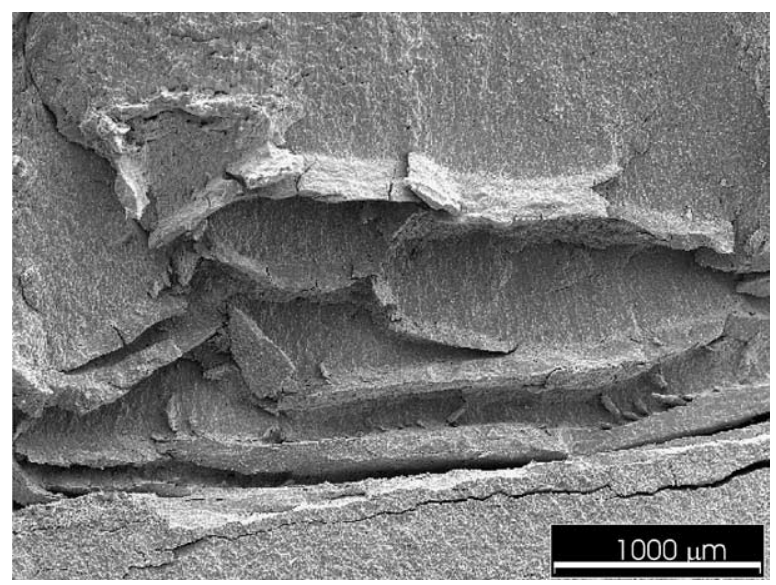

Fig. 7. Fracture surface showing the appearance of a noncommon area between the fatigue pre-crack region and the fracture itself.

corresponded to $K_{\mathrm{I}}$ values between 16 and $22 \mathrm{MPa} \sqrt{ } \mathrm{m}$, that is $J_{\mathrm{I}}$ values of 2.5 and $4.7 \mathrm{~kJ} /$ $\mathrm{m}^{2}$. Considering $K_{\mathrm{th}}$ or $K_{\mathrm{IH}}$ the threshold stress intensity factors necessary to cause the initiation of sub-critical crack propagation, a value of $K_{\text {th }}=20 \mathrm{MPa} \sqrt{ } \mathrm{m}$ has been reported [18] for a similar material at $473 \mathrm{~K}$ and hydrogen levels from 110 to $290 \mathrm{ppm}$. This supports the assumption that the crack might have grown during the $\mathrm{H}$ charging within the annealing process.

The fracture toughness results of specimens tested at different temperatures are plotted in Fig. 8. Fig. 8(a) shows $J$ values as a function of $\mathrm{H}$ content close to the crack-tip and Fig. 8(b) as a function of $\mathrm{H}$ content far away from the crack-tip.
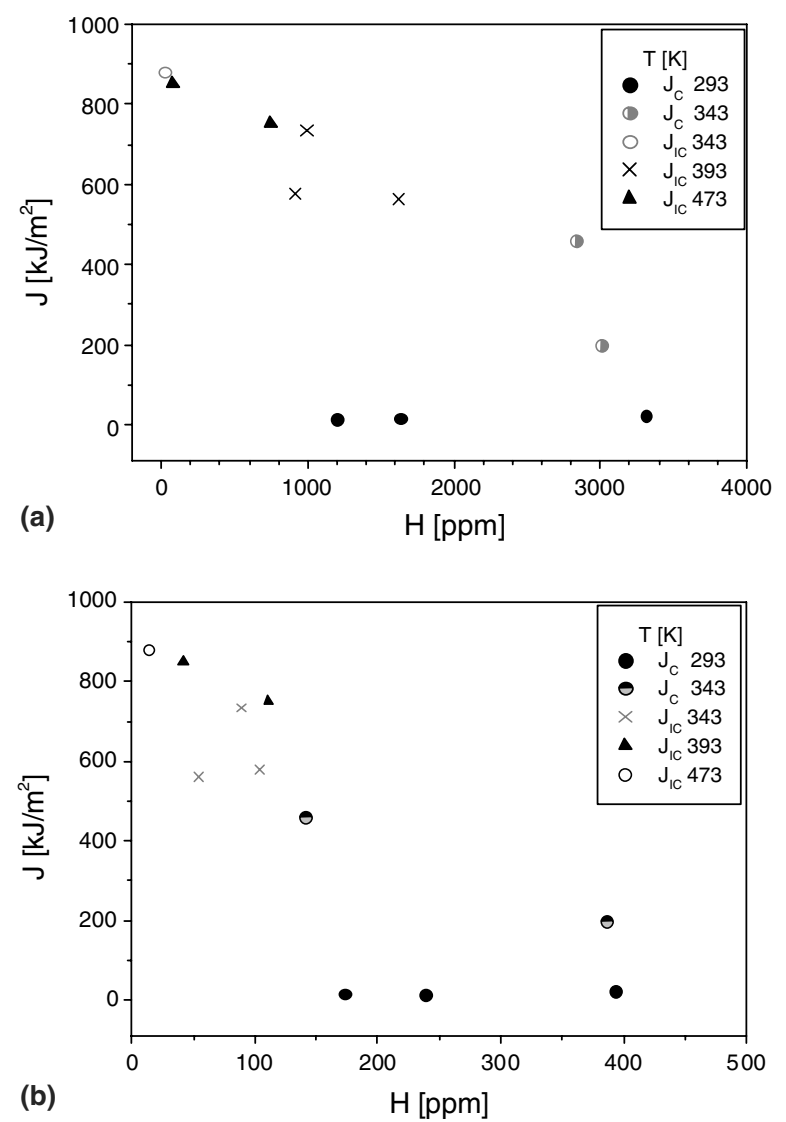

Fig. 8. $J$ values at different temperatures as a function of the $\mathrm{H}$ level: (a) near the crack-tip, and (b) far away from the crack-tip (at more than $8 \mathrm{~mm}$ from the crack-tip, corresponding to the bulk H content, see Fig. 2).

The fracture behaviour for the tests performed at $343 \mathrm{~K}$ was also brittle, as it was at room temperature, although the records showed a clear non-linearity, and some stable crack growth was observed before unstable fracture. At higher temperatures, instead, the influence of hydrogen diminished and ductile behaviour occurred. When results are plotted as a function of temperature, Fig. 9, a fracture mode transition can be observed between 343 and $393 \mathrm{~K}$. Analysis of data as a function of hydrogen content is more difficult because at high temperatures no tested specimen kept a high bulk $\mathrm{H}$ level. The observation of the fracture surfaces showed that the fracture micromechanism at high temperature was nucleation and growth of microvoids, Fig. 10, as was observed on specimens with homogeneous hydrogen distribution.

When the behaviour of specimens with preferentially orientated to the crack plane hydrides are compared to others with no preferentially oriented 


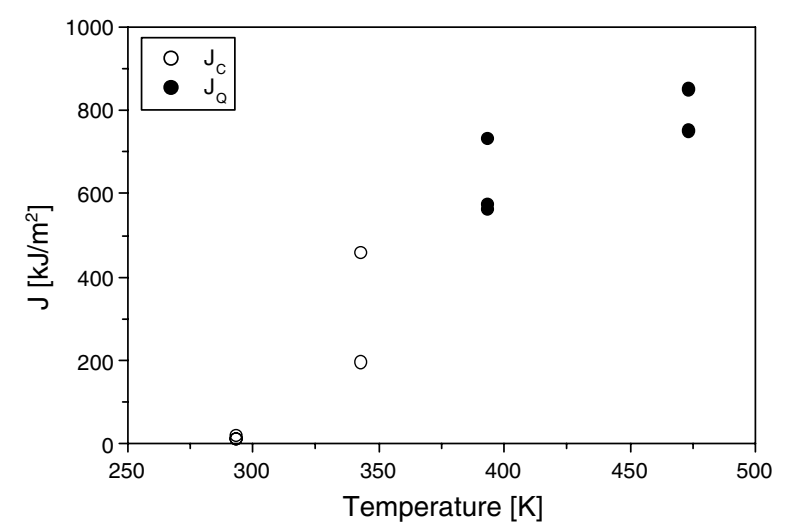

Fig. 9. $J$ values as a function of temperature.

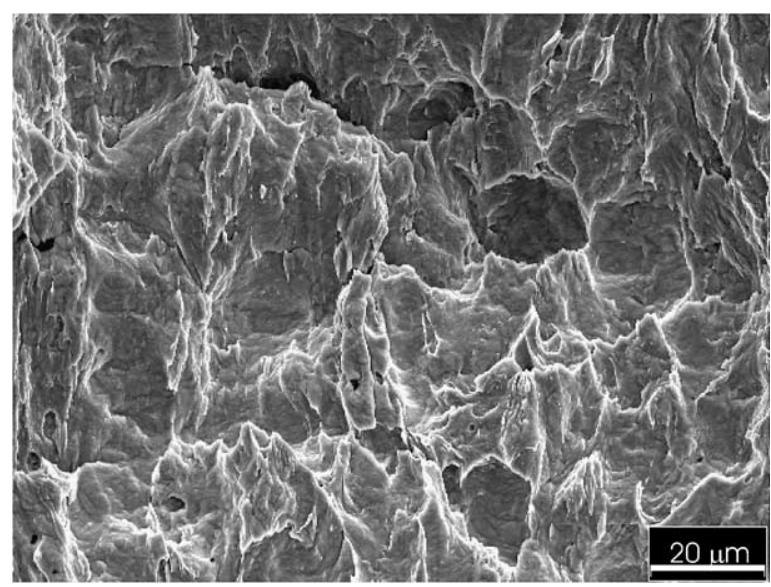

Fig. 10. Fracture surfaces of specimens tested at $473 \mathrm{~K}$.

hydrides, although having similar hydrogen content, fracture mode and fracture toughness prove quite different. The following examples depict this difference in tests at room temperature. For homogeneous hydrogen distribution up to $2000 \mathrm{ppm}$, ductile fracture was observed, while for hydrogen content around $1000 \mathrm{ppm}$ homogeneously distributed, the $J$ initiation values were around $90 \pm$ $5 \mathrm{~kJ} / \mathrm{m}^{2}$. In these cases, the hydrides were not preferentially oriented. In contrast, for a non-homogeneous distribution with 1200 ppm near the cracktip where the hydrides were orientated to the crack plane, brittle fracture occurred at $J_{\mathrm{C}}$ values around $15 \mathrm{~kJ} / \mathrm{m}^{2}$, Fig. 5. Therefore, both high H concentration and preferentially oriented to the crack plane platelets influence the fracture mode, enhancing brittle behaviour and displacing the ductile to brittle transition region.

It seems that the transition from ductile to brittle behaviour could be associated with both the hydride platelet orientation with respect to array on the crack path and the crack-tip region $\mathrm{H}$ content. A tensile stress field around a crack makes the hydride precipitate preferentially in an orientation favourable to crack propagation. An array of hydrides oriented preferentially to the crack plane near the crack-tip leads to high probability of finding a crack path mostly composed by hydrides, resulting in a sudden crack instability at a low fracture toughness value. When the matrix ductility is high enough (e.g. at high temperature), the matrix will deform around the fractured hydrides, thus avoiding brittle fracture and resulting in a stable crack growth and higher fracture toughness.

\section{Summary}

The influence of a hydrogen concentration gradient at the crack-tip on the fracture toughness, fracture mode, and micromechanisms of a Zircaloy-4 alloy was studied within a temperature range from 293 to $473 \mathrm{~K}$. Hydride stress-orientation due to the mechanical load imposed during hydrogen charging was observed. Platelets preferential precipitation plane was LS rather than LT, the precipitation plane for unstressed condition.

In the heterogeneous $\mathrm{H}$ distribution case, brittle fracture without previous stable crack growth was observed at room temperature, brittle fracture with some previous stable crack growth occurred at $323 \mathrm{~K}$, and the fracture mode was ductile at the highest testing temperature. In contrast, fracture behaviour was always ductile for homogeneous $\mathrm{H}$ distribution even at $2000 \mathrm{ppm} \mathrm{H}$. The main fracture micromechanism observed was cleavage for specimens that fractured in a brittle manner at low temperatures, and nucleation, growth and coalescence of microvoids for specimens that failed in a ductile way, especially at high temperature.

A change in fracture mode from ductile to brittle occurred when the hydrides were concentrated ahead the crack-tip and oriented parallel to the crack plane at the lowest temperatures. The ductile-to-brittle transition is dependent not only on the crack-tip hydrogen content but, also on the hydride platelet orientation.

\section{References}

[1] D.O. Northwood, U. Kosasih, Int. Met. Rev. 28 (2) (1983) 92.

[2] R.N. Shingh, R. Kishore, S.S. Singh, T.K. Sinha, B.P. Kashyap, J. Nucl. Mater. 325 (2004) 26. 
[3] P.K. De, J.T. John, V.V. Raman, S. Banerjee, J. Nucl. Mater. 203 (1993) 94.

[4] R.L. Eadie, C.E. Coleman, Scr. Metall. 23 (1989) 1865.

[5] C.E. Ells, J. Nucl. Mater. 28 (1968) 129.

[6] L.A. Simpson, Metall. Trans. A 12A (1981) 2113.

[7] F. Prat, M. Grange, J. Besson, E. Andrieu, Metall. Mater. Trans. A 29A (1998) 1643.

[8] M. Kuroda, S. Yamanaka, D. Setoyama, M. Uno, K. Takeda, H. Anada, F. Nagase, H. Uetsuka, J. Alloys Compds. 330-332 (2002) 404.

[9] G. Bertolino, G. Meyer, J. Perez Ipiña, J. Nucl. Mater. 320 (3) (2003) 272.

[10] M. Grange, J. Besson, E. Andrieu, Metall. Mater. Trans. A 31A (2000) 679.

[11] R.S. Daum, S. Majumdar, M.C. Billone, D.W. Bates, D.A. Koss, A.T. Motta, in: 13th ASTM International Symposium on $\mathrm{Zr}$ in the Nuclear Industry, ASTM STP 1423, Annecy, France, 2001, p. 702.

[12] O.N. Pierron, D.A. Koss, A.T. Motta, K.S. Chan, J. Nucl. Mater. 322 (1) (2003) 21.

[13] ASTM, Standard Test Method for Measurement of Fracture Toughness, ASTM E 1820-99, Annual Book of ASTM Standards, vol. 03.01, ASTM, 1999, p. 972.

[14] J.E. Perez Ipiña, Eng. Fract. Mech. 36-5 (1990) 797.

[15] D. Hardie, M.W. Shanahan, J. Nucl. Mater. 55 (1975) 1.

[16] L.G. Bell, R.G. Duncan, AECL Report No. 5110, 1975.

[17] G. Bertolino, G. Meyer, J. Perez Ipiña, J. Nucl. Mater. 322 (1) (2003) 57.

[18] J.H. Huang, C.S. Ho, Mater. Chem. Phys. 47 (1997) 184. 